\title{
Endoscopic ultrasound fine-needle aspiration of peritoneal deposits for diagnosis of tubercular peritonitis in a cirrhotic patient with ascites
}

A 30-year-old man, known to have alcohol-related cirrhosis, presented with tiredness and loss of appetite. He had stopped drinking alcohol 1 year ago when he was diagnosed with cirrhosis and was prescribed diuretics. An ultrasound performed 6 months later did not show ascites and the diuretics were stopped. However, the ascites reaccumulated 1 month prior to presentation. Laboratory investigations revealed serum albumin of $3.1 \mathrm{~g} / \mathrm{dL}$. An ultrasound of the abdomen revealed features of chronic liver disease with ascites. Ascitic fluid analysis revealed high gradient, lymphocytic nonmalignant ascites with an adenosine deaminase level of $28 \mathrm{IU} / \mathrm{L}$. An ascitic fluid culture as well as polymerase chain reaction (PCR) for Mycobacterium tuberculosis were negative. Computed tomography (CT) of the abdomen revealed findings similar to the ultrasound findings, and the lung parenchyma was normal on CT chest. Endoscopic ultrasound (EUS) of the stomach revealed ascites and peritoneal deposits, visualized as hyperechoic rounded lesions ( Fig. 1).

Perigastric and periesophageal collaterals were also noted ( $\bullet$ Figs. 2 and $\mathbf{3}$ ).

EUS fine-needle aspiration (FNA) of the peritoneal deposits was carried out, carefully avoiding the venous collaterals. On withdrawal of the echoendoscope, a 1.4-cm subcarinal lymph node was noted ( $\bullet$ Fig. 4) and EUS FNA of the lymph node was carried out.

Cytological examination of the peritoneal deposits revealed inflammatory cells, and PCR for M. tuberculosis was positive. Cytological examination of the lymph node FNA sample revealed epithelioid cell granulomas ( Fig. 5).

The patient was started on antitubercular therapy and his condition subsequently improved.

Tubercular peritonitis lacks specific signs, and its diagnosis becomes more difficult in cirrhotic ascites. In addition, investigations routinely used for diagnosis of tubercular ascites can be negative, thereby delaying diagnosis and treatment [1-3]. EUS FNA of peritoneal lesions seems to be a safe, minimally invasive alternative for tissue diagnosis in ascitic patients pre-

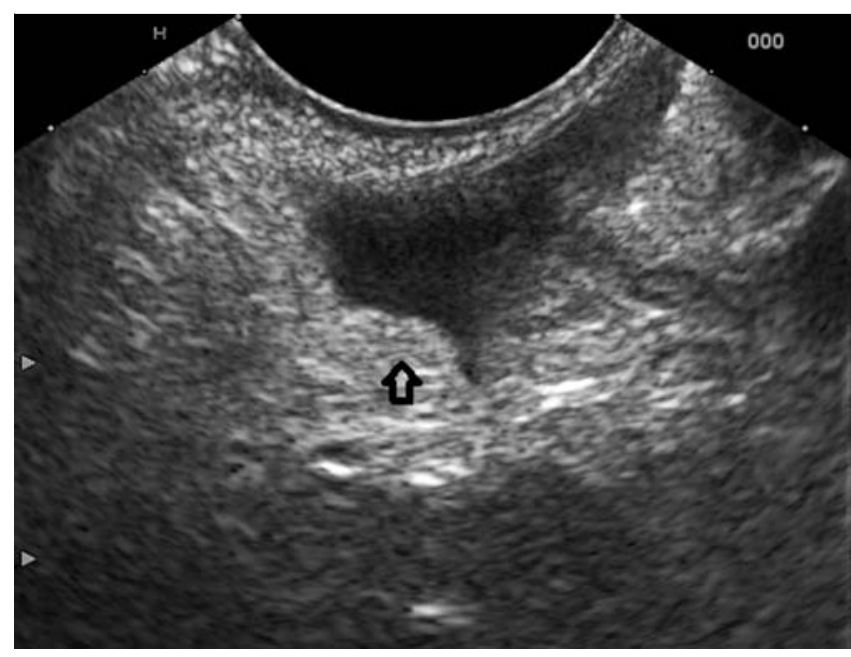

Fig. 1 Endoscopic ultrasound of the stomach showing ascites along with hyperechoic peritoneal deposits (arrow).

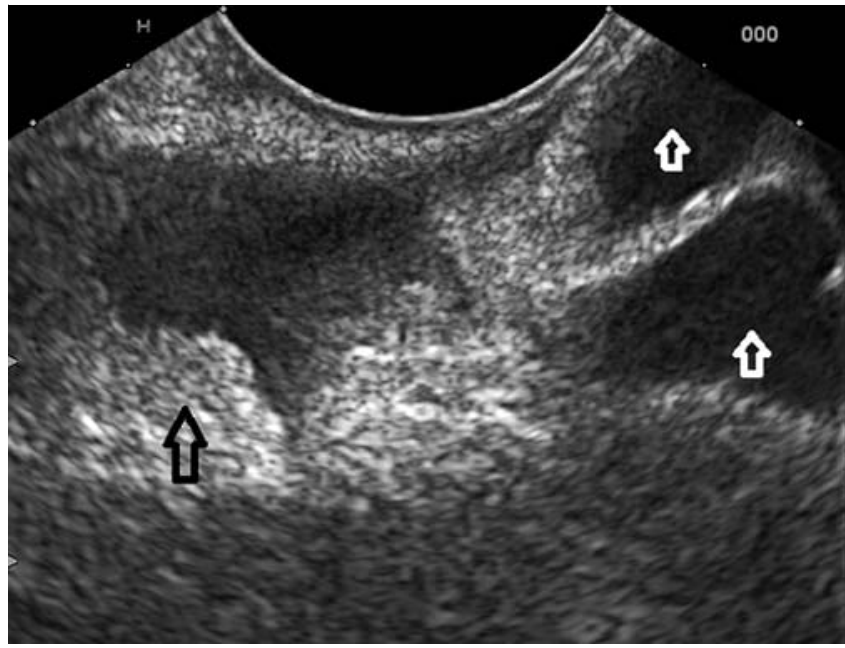

Fig. 2 Ascites, hyperechoic peritoneal deposits (black arrow), and venous collaterals (white arrow)

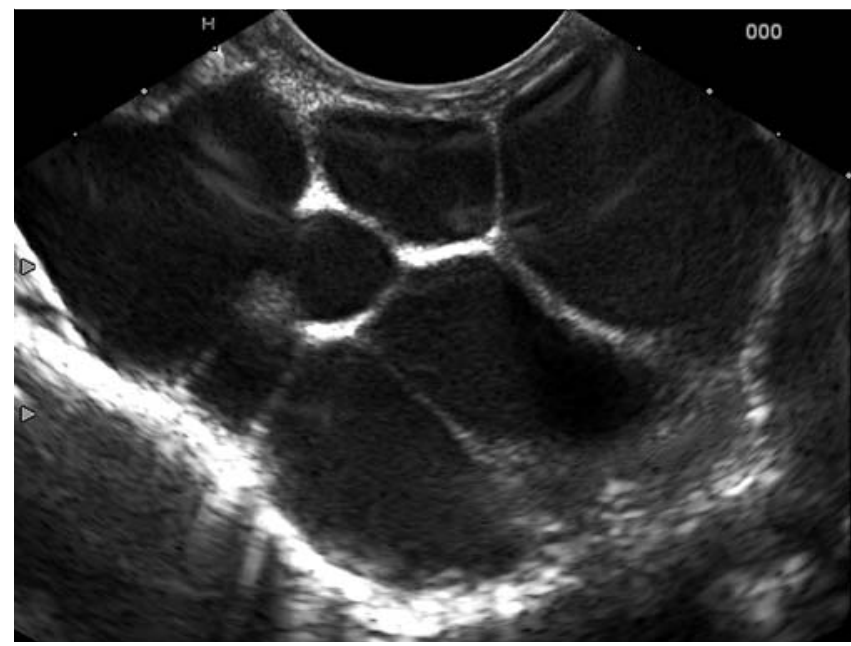

Fig. 3 Large periesophageal collaterals. 


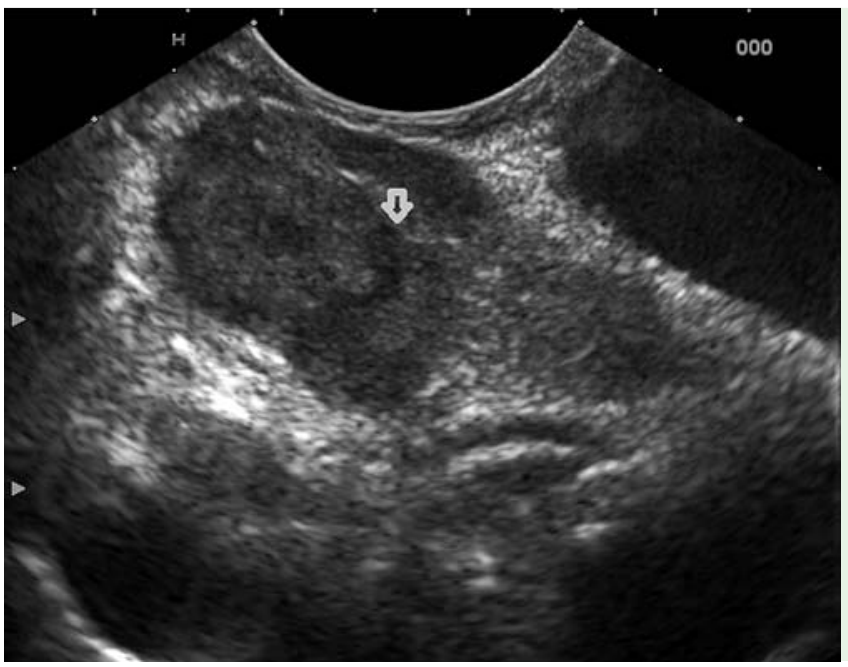

Fig. 4 Subcarinal lymph node with hypoechoic areas (arrow).

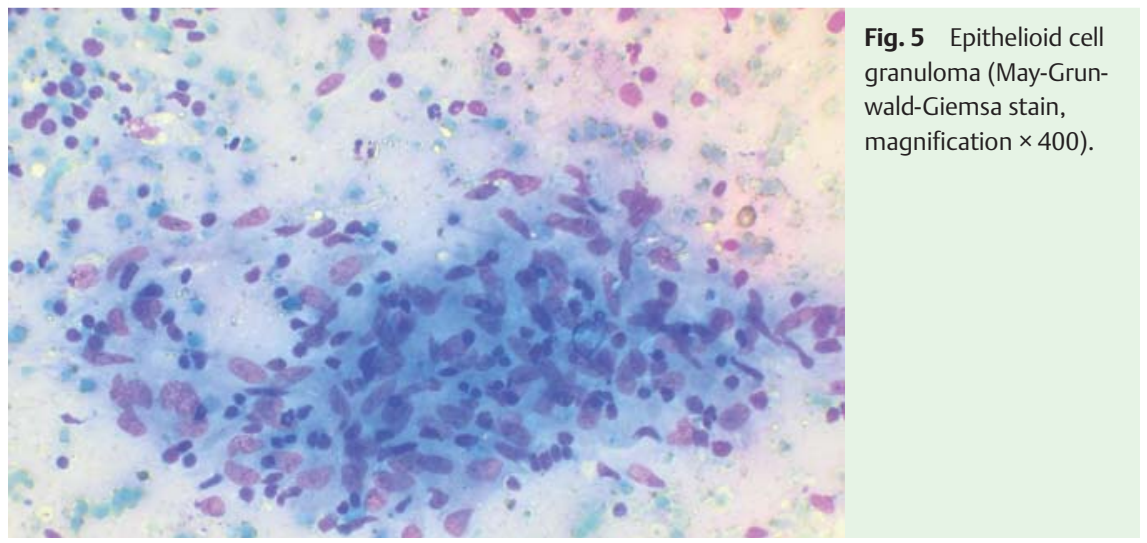

senting a diagnostic dilemma [4]. We have previously reported a patient with exudative malignant ascites, in whom EUS FNA of peritoneal deposits helped to reach the correct diagnosis [5]. Also, with EUS it is possible to screen for presence of mediastinal lymph nodes and carry out guided FNA, as we did in our case.

\section{Competing interests: None}

Endoscopy_UCTN_Code_CCL_1AF_2AG_3AD

\author{
S. S. Rana ${ }^{1}$, D. K. Bhasin ${ }^{1}$, R. Srinivisan ${ }^{2}$, \\ K. Singh ${ }^{1}$ \\ 1 Department of Gastroenterology, Post \\ Graduate Institute of Medical Education \\ and Research (PGIMER), Sector 12, \\ Chandigarh - 160012, India \\ 2 Department of Cytology, Post Graduate \\ Institute of Medical Education and \\ Research (PGIMER), Sector 12, \\ Chandigarh - 160012, India
}

\section{References}

1 Hillebrand DJ, Runyon BA, Yasmineh WG et al. Ascitic fluid adenosine deaminase insensitivity in detecting tuberculous peritonitis. Hepatology 1994; 19: 731

2 Akhan 0 , Pringot $J$. Imaging of abdominal tuberculosis. Eur Radiol 2002; 12: 312 - 323

3 Shimozuma Y, Ito T, Ishii S et al. Two cases of tuberculous peritonitis with liver cirrhosis complicated by refractory ascites. Clin J Gastroenterol 2009; 4: 300-305

4 Peter S, Eltoum I, Eloubeidi MA. EUS-guided FNA of peritoneal carcinomatosis in patients with unknown primary malignancy. Gastrointest Endosc 2009; 70: 1266 - 1270

5 Rana SS, Bhasin DK, Singh K. EUS-guided FNA of peritoneal carcinomatosis. Gastrointest Endosc (in press)

Bibliography

DOI $10.1055 / \mathrm{s}-0030-1255800$

Endoscopy 2010; 42: E306-E307

(c) Georg Thieme Verlag KG Stuttgart · New York . ISSN 0013-726X

\section{Corresponding author}

\section{Dr. S. S. Rana}

Department of Gastroenterology

Postgraduate Institute of Medical Education and Research (PGIMER)

Chandigarh - 160012

India

Fax: +91-172-2744401

drsurinderrana@yahoo.co.in,

sonalisurinder@yahoo.co.in 